\title{
A cidade e a Copa do Mundo: projetos e transformações urbanas em Porto Alegre - Brasil
}

\author{
Mario Leal-Laborgue. Universidade Federal do Rio Grande do Sul (UFRGS), Porto \\ Alegre, Brasil. \\ Amanda Cabette. Universidade Federal do Rio Grande do Sul (UFRGS), Porto Alegre, \\ Brasil.
}

RESUMO | A cidade de Porto Alegre será uma das sedes dos jogos da Copa do Mundo FIFA 2014 no Brasil. Por causa disso, estão previstas várias obras de adequação da infraestrutura urbana para que a cidade esteja preparada para o momento dos jogos. Este texto apresenta quais são as obras acordadas entre os órgãos públicos brasileiros e a FIFA, sua localização no território da cidade e quais os impactos previstos no espaço urbano. Também contextualiza brevemente a forma como se tem produzido o espaço na cidade nas últimas décadas, com o intuito de demonstrar que algumas formas que pareciam superadas reaparecem no momento atual. Por fim, discute as conseqüências destas transformações para a cidade como um todo e seus cidadãos, questionando o tipo de legado que Porto Alegre pode ter com a Copa do Mundo.

PALAVRAS-CHAVE | política urbana, geografia urbana, transformações sócio-territoriais.

ABSTRACT | The city of Porto Alegre is one of the venues of the 2014 FIFA World Cup games in Brazil. Because of this, several works to adequate the city urban infrastructure have been planned to prepare the city for the tournament. This paper presents the works which are agreed between FIFA and the Brazilian government agencies, their location within the city and what their expected impacts on urban space. It also briefly contextualizes how the urban space has been produced in recent decades with the aim of demonstrating that some forms that seemed to have been overcome reappear at this moment. Finally, it discusses the consequences of these changes for the city as a whole and its citizens, questioning the kind of legacy that the World Cup will leave in Porto Alegre.

KEY WORDS | urban policy, urban geography, socio-territorial transformations. 


\section{Introdução}

Porto Alegre, capital do Estado do Rio Grande do Sul e uma das principais metrópoles brasileiras, foi escolhida como uma das subsedes para a Copa do Mundo FIFA 2014 no Brasil. Esta escolha tem duas conseqüências básicas: 1) a modernização do estádio Beira-Rio, pertencente ao Sport Club Internacional e indicado como local para a realização dos jogos na cidade e 2) um conjunto de intervenções no espaço urbano que são as obras de adequação das cidades-sedes, tanto por uma exigência da FIFA como por uma vontade dos poderes públicos brasileiros em aproveitar a oportunidade para a realização de transformações estruturais na paisagem urbana, como uma modernização deste espaço para os moradores, além de torná-lo mais agradável e atrativo para futuros turistas e visitantes.

São estas obras e intervenções a base para os principais objetivos deste texto: descrever e discutir tanto a maneira como as ações estão ocorrendo, como as consequências destas intervenções no território da cidade, além de debater o legado que um evento como este deixará no espaço urbano. A grande questão é que não se modifica o espaço, se conformam paisagens e se reordena o território, sem consequências. O que são as obras previstas para Porto Alegre? Como elas se articulam no espaço da cidade? Quais são as consequências para o município e seus habitantes, quando todas as obras estiverem prontas? Qual a relação entre as obras projetadas e a concepção de gestão urbana colocada em prática pela atual administração municipal? São estas questões que este texto pretende começar a responder.

Deve ser ressaltado que no momento em que este trabalho está sendo publicado, as obras planejadas ainda estão em andamento, com variados graus de execução e finalização. Ainda assim, os autores partem do princípio que é possível projetar, em larga medida, os resultados mais gerais destes processos pois, o espaço geográfico como ensina Milton Santos (1996), é um conjunto indissociável de sistema de objetos e sistema de ações. A definição deste espaço geográfico varia com a natureza dos objetos e a natureza das açôes presentes em cada momento histórico e a natureza das ações atuais em Porto Alegre é objeto deste estudo. As várias obras em andamento na cidade devem ser vistas como parte de um sistema de açôes, com a intencionalidade do Poder Público Municipal em modificar o espaço da cidade. Esta intencionalidade torna o Governo Municipal o principal agente das transformações associadas à Copa 2014. Este processo, atualmente comandado pelas ações governamentais, é contraditório, pois:

Quando a sociedade age sobre o espaço, ela não o faz sobre os objetos como realidade física, mas como realidade social, formas-conteúdo, isto é, objetos sociais já valorizados aos quais ela (a sociedade) busca oferecer ou impor um novo valor. A ação se dá sobre objetos já agidos, isto é, portadores de ações concluídas, mas ainda presentes. Esses objetos da ação são, desse modo, dotados de uma presença humana e por ela qualificados. A dialética se dá entre ações novas e uma 'velha' situação, um presente inconcluso querendo realizar-se sobre um presente perfeito. (Santos, 1996, p. 88) 
Exatamente porque toda ação se dá sobre objetos já agidos que é importante, não só descrever as obras projetadas e em execução, como se faz na primeira seção deste trabalho, mas apresentar o contexto histórico mais recente. Este é o foco da segunda seção. $\mathrm{O}$ atual Governo teve como herança e age em cima de um processo em que a idéia e a prática de participação popular nas decisões governamentais foi exemplificada no Orçamento Participativo, que não desapareceu de todo na política urbana, mas foi subordinado à idéia de Governança Local. A terceira seção discute as conseqüências que as transformações urbanas poderão trazer para o território do município e as perspectivas para a população da cidade.

Além da breve revisão bibliográfica e histórica das formas de ocupação e produção do espaço em Porto Alegre, este texto está fundamentado nos dados oficiais sobre a situação da cidade, tendo como fontes primárias levantamentos demográficos do Instituto Brasileiro de Geografia e Estatística (IBGE), estudos e projetos disponibilizados pela Prefeitura Municipal de Porto Alegre e os documentos referentes à matriz de Responsabilidades que balizam as ações governamentais relacionadas às obras da Copa do Mundo FIFA 2014.

\section{As obras projetadas}

No dia 13 de janeiro de 2010, a União, por intermédio do Ministério do Esporte, o Governo do Estado do Rio Grande do Sul e a Prefeitura Municipal de Porto Alegre assinaram um documento intitulado Matriz de Responsabilidades, com o objetivo de viabilizar a execução de ações governamentais consideradas necessárias à realização da Copa do Mundo FIFA 2014. Na cláusula terceira, "das responsabilidades dos partícipes", foram assinaladas e divididas as atribuições das intervenções associadas à competição. É possível ler ali que, ao Estado e/ou Município, compete executar e custear obras referentes a:

a) Mobilidade urbana;

b) Entorno dos estádios;

c) Entorno dos aeroportos;

d) Entorno de terminais turísticos portuários.

Quanto à União cabe executar e custear intervenções em:

a) Aeroportos: terminais de passageiros, pistas e pátios;

b) Portos: terminais turísticos.

Uma coisa já chama a atenção, mesmo antes de se examinar as obras projetadas: mobilidade é, sem dúvida, a principal preocupação e alvo das intervenções das autoridades governamentais, seja porque aparece em primeiro lugar o item mobilidade urbana, seja porque se projetam obras no entorno de áreas do território concentradoras de população em trânsito.

Sem desprezar a importância das intervenções diretas da União, principalmente no caso de Porto Alegre - a ampliação e aumento da capacidade do Aeroporto 
Salgado Filho, o foco principal aqui estará nas obras sob a responsabilidade direta do Estado/Município, pelo potencial de alterar formas de ocupação do território e organização do espaço da cidade. Pois então, que obras foram acordadas pela Matriz de Responsabilidades? Ela está dividida em apenas duas partes: anexo A "mobilidade urbana" e anexo B "Estádio/Arena". Como a reforma do Estádio Beira-Rio é uma obra privada, de responsabilidade do Sport Club Internacional e com pouca capacidade de alterar o espaço, não será objeto principal de atenção neste estudo.

O anexo A compreende obras no valor total previsto no início de 2010 de $\mathrm{R} \$$ 524,9 milhões (ou aproximadamente 340 milhões de dólares, pelo câmbio de julho de 2011), um volume de dinheiro para intervenções urbanas como há muito não se tinha notícia em Porto Alegre.

Estão previstos os seguintes alargamentos e ampliações de vias, com seus respectivos valores (como pode ser visualizado no mapa da Figura 1):

a) Corredor Avenida Tronco, com um total de R $\$ 133,6$ milhões: alargamento de via com extensão de $3,4 \mathrm{~km}$, contemplando 3 pistas para automóveis em cada sentido mais corredor exclusivo para ônibus. A Prefeitura prevê remoções de mais de 1.500 famílias para a realização da obra.

b) Duplicação da Av. Edvaldo Pereira Paiva com total de 5,8 km e custo previsto de R \$ 78,2 milhões; a avenida é uma importante via de ligação entre o centro da cidade e o estádio Beira-Rio, servindo também como alternativa de trânsito para automóveis que se dirigem para a zona sul da cidade.

c) Corredor Rua Voluntários da Pátria e terminal de ônibus São Pedro: R \$ 30 milhões; via antiga e em alguns pontos deteriorada de ligação entre o centro e a zona norte da cidade. Prevista a duplicação (alargamento) de 3,5 km. Deverá ser uma via alternativa em relação à principal avenida de acesso rodoviário a Porto Alegre, a Avenida Presidente Castelo Branco. Pretende-se que impulsione o desenvolvimento e a revitalização do Quarto Distrito e do Bairro Humaitá, antigos bairros industriais deteriorados e com infraestrutura subaproveitada. ${ }^{1}$

d) Prolongamento da Av. Severo Dullius, com custo de R $\$ 24$ milhões. Tem como objetivo melhorar e qualificar o acesso entre a Avenida Assis Brasil e o Aeroporto Internacional Salgado Filho, com aproximadamente $2 \mathrm{~km}$ de extensão.

e) Complexo da Rodoviária, com valores de $\mathrm{R} \$ 21$ milhões. Execução de um viaduto ligando a Avenida Júlio de Castilhos à Castelo Branco, a instalação de uma parada de ônibus no canteiro central em frente à Rodoviária e outras pequenas intervençôes para resolver o "conflito" entre ônibus e automóveis existente no local. O conflito se refere ao fato de os ônibus terem uma parada ao lado da estação rodoviária, no lado direito da via e depois se dirigirem à esquerda para os terminais urbanos no Centro. Ao mesmo tempo, uma parcela dos

1 Mesmo que a duplicação ainda não esteja completa no momento (fim de 2012), um fato mostra que está havendo indução de novos investimentos para esta área: o outro time de futebol da cidade, o Grêmio de Football Portoalegrense acaba de inaugurar sua nova Arena de esportes exatamente nesta região, onde também haverá novas torres residenciais e comerciais conformando um novo vetor de investimento imobiliário na cidade. 
automóveis faz um percurso que cruza com os coletivos em direção contrária, indo para a esquerda em direção à Av. Castelo Branco.

f) Corredor da $3^{a}$ Perimetral, com total de $\mathrm{R} \$ 120,4$ milhões. Esta Perimetral foi a última grande intervenção no tecido urbano da capital, considerada atualmente a maior via urbana da cidade com 12,3 km de extensão ligando as zonas Norte e Sul. Mesmo tendo sido inaugurada recentemente (em 2006), depois de uma obra que custou $\mathrm{R} \$ 113$ milhões, pretende-se facilitar o tráfego e diminuir a lentidão e saturamento da via, com a construção de dois viadutos e três passagens de nível em importantes cruzamentos da Avenida.

Além destas intervenções, a Matriz de Responsabilidades também prevê a implantação de um sistema para qualificação do transporte coletivo da cidade conhecido como BRT (Bus Rapid Transit). Um dos objetivos, além de modernizar a frota e o sistema de transporte público, é diminuir o volume de viagens em direção ao Centro, pois se considera que muitos ônibus chegam ao Centro subutilizados somente contribuindo com os engarrafamentos. Assim, os passageiros procedentes dos bairros da Capital e da Região Metropolitana deverão desembarcar nos Portais (localizados em pontos estratégicos) e no terminal Triângulo (zona Norte da cidade). A partir daí, tomarão ônibus articulados especiais para seguir viagem dentro da cidade até o Centro. As obras do BRT estavam inicialmente divididas em 3 trajetos básicos que levam o nome da principal avenida onde deveria ocorrer a implantação do sistema:

a) BRT Assis Brasil de R $\$ 28$ milhões, compreendendo 7 estações a partir do terminal Triângulo em direção ao centro, com extensão de 4,4 km;

b) BRT Protásio Alves, obra de R\$53 milhões prevendo 11 estações a partir da confluência da Terceira Perimetral até a estação rodoviária, com extensão total de $9,4 \mathrm{~km}$;

c) BRT Bento Gonçalves, projeto de R $\$ 23$ milhões com 12 estações e $6,5 \mathrm{~km}$ de extensão. Nesta mesma obra estão previstas as construções dos Portais Azenha (no bairro de mesmo nome e próximo ao Centro) e Antônio de Carvalho (na zona Leste em direção ao Campus do Vale da Universidade Federal do Rio Grande do Sul (UFRGS) e da cidade de Viamão). Deve-se salientar que estes Portais estão localizados em antigas estações de transbordo construídas durante a década de 80 para um Sistema Integrado de Transporte, que foi desativado pouco tempo depois de sua inauguração, alvos de muita reclamação dos usuários e considerados ineficientes. Assim, não haverá custos de desapropriação e sim adequação de áreas pré-existentes e atualmente subutilizadas.

Atualmente, a requalificação do sistema de transporte coletivo está um pouco modificada porque, depois da assinatura da Matriz de Responsabilidades, Porto Alegre foi contemplada pelo Governo Federal no "PAC da Mobilidade" com a garantia da construção de um metrô que passará por baixo da Av. Assis Brasil. Com isso, o BRT desta Avenida foi retirado da Matriz das obras viárias, se estendeu o BRT Protásio Alves para um pouco além da Terceira Perimetral até a Av. Manuel 
Elias e foi incluído BRTs na Av. João Pessoa até o centro histórico (que na verdade é uma continuação do BRT Bento Gonçalves).

\section{FIGURA 1 | Localização das intervenções no território de Porto Alegre}

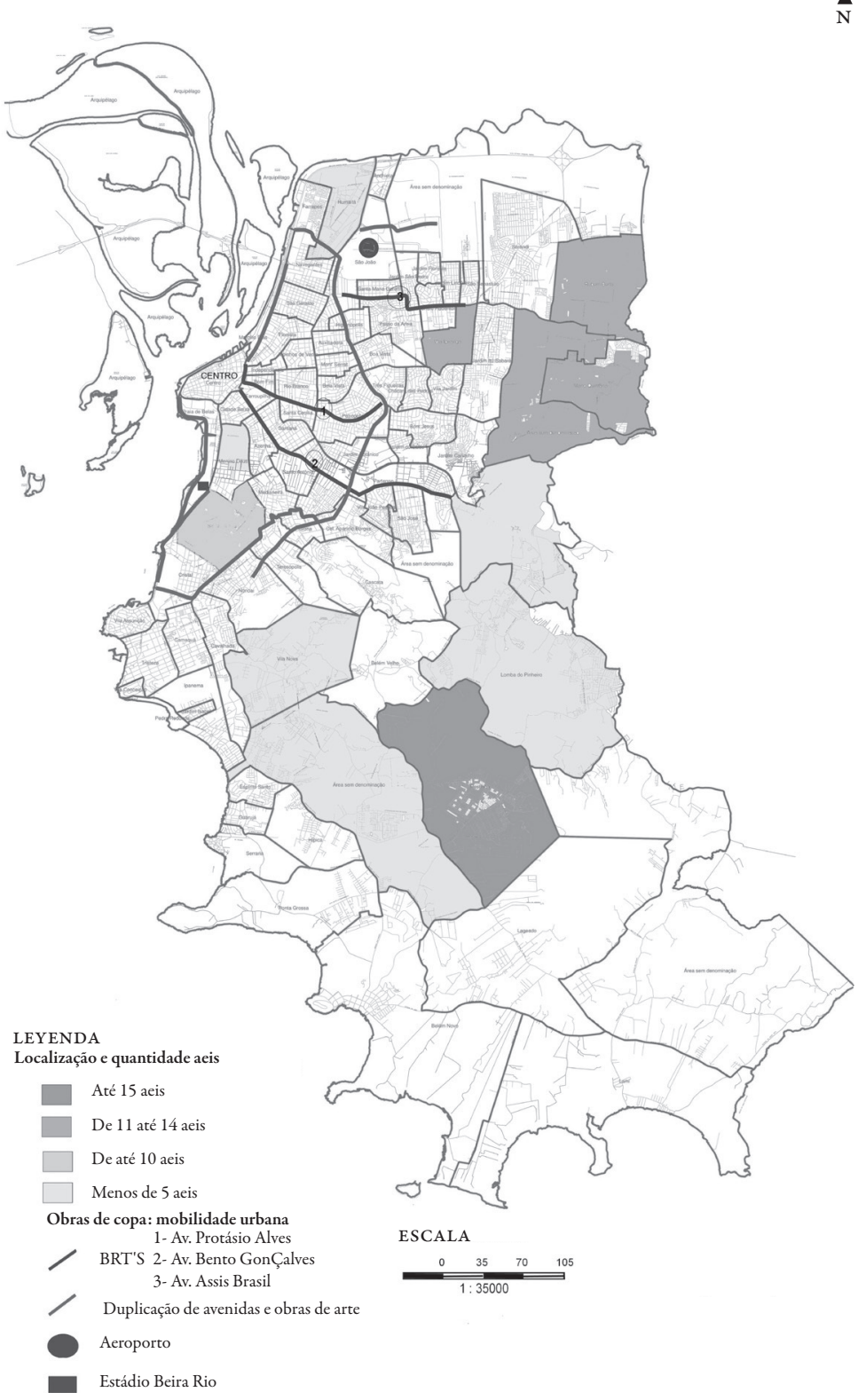

FONTE ELABORAÇÃO DO AUTOR. BASEADO EM PREFEITURA MUNICIPAL DE PORTO ALEGRE (2009) 
Por fim, cabe mencionar novamente a parte da Matriz de Responsabilidades correspondente à União, a ampliação e modernização do aeroporto. Incluída nas prioridades da Copa, na verdade o projeto de ampliação é anterior à escolha do Brasil como Sede da competição da FIFA. O que aconteceu é que, com a Copa, a modernização/ampliação do aeroporto passou de uma das obras listadas no Programa de Aceleração do Crescimento (PAC) ligado à infraestrutura, para uma obra prioritária com prazo de finalização anterior ao começo da competição internacional. Existe também uma questão técnica: a ampliação do comprimento da pista (o projeto original) não tem nenhuma relação direta com a Copa, relacionava-se com a ampliação da capacidade de carga e pouso e decolagem de avióes cargueiros de grande porte; o que com certeza vai ajudar no período da competição são obras de ampliação do terminal de passageiros e a instalação de equipamento (não existente hoje) de navegação aérea sob neblina. Agora, o que sem dúvida tem relação com o tema tratado aqui é uma das conseqüências das obras no Salgado Filho: a ampliação só é possível com o reassentamento de uma ocupação irregular no entorno do aeroporto: a Vila Dique. A mesma está sendo transferida para o loteamento da Avenida Bernardino Silveira Amorim, 1.915, no Bairro Rubem Berta, distante cerca de 4 km do aeroporto e, portanto, mais afastado ainda do centro da cidade. Cerca de 400 famílias já foram transferidas para o novo local e, quando concluído, o loteamento que ocupa uma área de 21 hectares terá um total de 1.476 habitações, 103 unidades comerciais, unidade de triagem de resíduos recicláveis, centro comunitário e creche (assim prometido pela Prefeitura). Mesmo sendo uma obra de responsabilidade do Governo Federal, a construção de novas unidades habitacionais e reassentamento das famílias é tarefa do município pela legislação brasileira. Assim, o dinheiro para isso não é um financiamento, mas um repasse de verbas do Governo Federal para o município. O que veremos mais a seguir é que a forma de resolver a questão da Vila Dique por parte da Prefeitura assemelha-se com a solução proposta e planejada para outros casos relacionados com as obras da Copa.

\section{A cidade no contexto}

Como é a Porto Alegre na qual estas obras todas estão sendo projetadas? Nos últimos anos, a cidade ficou internacionalmente conhecida por dois motivos basicamente: como sede do Fórum Social Mundial e como lugar de inovação democrática, através da introdução do Orçamento Participativo (OP).

Contando atualmente com 1.409.351 habitantes, o crescimento populacional na última década foi extremamente baixo. Segundo os dados preliminares divulgados pelo IBGE sobre o censo 2010, em números absolutos, o aumento da população foi de apenas 48.935 habitantes, com uma taxa de crescimento correspondente a $0,35 \%$ ao ano. É a menor taxa de crescimento entre as capitais brasileiras. Isto tem um significado inédito para as políticas públicas: ao longo do século XX, uma das desculpas tradicionais para o aumento do déficit habitacional, da pobreza e da 
irregularidade fundiária era dizer que o crescimento populacional era maior que o crescimento da capacidade de resolução dos problemas por parte do poder público.

Isto fica muito bem representado entre as décadas de 50 e 70 do século passado, exatamente durante a fase em que a cidade mais cresceu (de 394.151 para 885.545 habitantes em vinte anos). Este período corresponde também ao auge da participação da indústria porto-alegrense no total da renda interna do Estado do Rio Grande do Sul, oscilando entre 27 e 25\% entre as décadas de 1930 e 1970 . Não por acaso, o decréscimo da participação relativa de Porto Alegre no total da renda interna do Rio Grande do Sul corresponde à diminuição no ritmo de crescimento demográfico, assim como o período de maior importância industrial da cidade produziu grande crescimento populacional. São dados que só reforçam a clássica ligação entre industrialização e urbanização, entre desenvolvimento capitalista e crescimento das cidades. O processo de urbanização implica na criação de uma grande quantidade de infraestruturas físicas para a produção, circulação e consumo de mercadorias, atrai uma grande quantidade de pessoas que também acabam por se transformar tanto em mercadorias (força de trabalho) como consumidoras de produtos e assim sucessivamente.

Em Porto Alegre, estas décadas de crescimento industrial/populacional vão dar início a um processo mais intenso de expansão da mancha urbana, marcando também as primeiras tentativas mais efetivas de regular a ocupação do solo na cidade (o primeiro Plano Diretor formalmente reconhecido como tal na cidade é de 1959). Vale a pena acompanhar a descrição de Beatriz Morem da Costa (2001, p. 10):

O crescimento populacional alterou a paisagem urbana, induzindo a Prefeitura de Porto Alegre, já no início da década de 50 , a disciplinar a atividade dos especuladores imobiliários através da criação de nova Legislação (Lei 1233/54). A regulamentação dos loteamentos urbanos na capital, impondo normas para a produção de novos lotes, levou à elevação de seus valores de mercado. Em consequência disso, os serviços de infraestrutura urbana, as residências de maior renda e as atividades de comércio e serviços concentraram-se, principalmente, na área central e às margens das principais avenidas, deslocando a moradia dos trabalhadores pobres para os espaços localizados na periferia da capital, que ainda não possuíam normas reguladoras de uso do solo urbano e nem eram objeto de especulação imobiliária. Com isso, houve uma expansão da ocupação de novas áreas na cidade e fora dela, ocasionando o surgimento de novos núcleos que viriam a se tornar os municípios de Alvorada e Cachoeirinha, ambos criados em 1965. Gravataí e esses dois municípios aumentaram significativamente o tamanho de sua população na década de 197080 , apresentando taxas médias de crescimento populacional de 7,4\%, 8,5\% e 7,4\% respectivamente.

Como se pode ver, o processo de periferização da pobreza não só é antigo, mas foi parcialmente incentivado por medidas governamentais. $\mathrm{O}$ que é interessante notar é exatamente isso: a localização dos mais pobres em áreas afastadas não foi só uma questão de mercado. As decisões de localização dos mais pobres não seguiram uma “mão invisível urbana”, capaz de alocar eficazmente os recursos e as decisões 
das famílias para moradia ${ }^{2}$. As políticas urbanas de regulação do uso do solo, de construção de novas unidades habitacionais e outras, ajudaram a criar as condições para que a tradicional dualidade centro/periferia ganhasse força no espaço da cidade. Se hoje em dia não se pode falar de dualidade em termos absolutos, também não se pode esquecer a persistência desta estruturação do espaço intra-urbano porto-alegrense: os bairros mais centrais ainda são os melhores servidos por infraestrutura e onde vivem classes mais altas; a periferia ainda apresenta carência de infraestrutura e é onde, de modo geral, vivem as classes mais pobres. É esta persistência na paisagem de formas espaciais fixas, marcadas por relações sociais, que Milton Santos chama de rugosidades (Santos, 1980, p. 138): "As rugosidades são o espaço construído, o tempo histórico que se transformou em paisagem, incorporado ao espaço." E é sobre este espaço que Porto Alegre vai crescer e se transformar no que ela é hoje.

Este panorama foi encontrado pela coligação de Partidos (liderada pelo PT - Partido dos Trabalhadores) que durante 15 anos governou o município, introduzindo inovações como o Orçamento Participativo e trazendo o Fórum Social Mundial para a cidade.

Mesmo que atualmente esta coligação esteja há dois mandatos fora da Prefeitura, o OP ainda existe. Isto mostra como continua sendo importante discutir esta política e suas conseqüências sobre o território da cidade. O Orçamento Participativo, do ponto de vista das ciências que se ocupam do espaço, é a afirmação da assertiva clássica de Claude Raffestin de que "o território é um espaço onde se projetou um trabalho, seja energia e informação, e que por consequência, revela relações marcadas pelo poder." (Raffestin, 1993, p. 144). Toda a lógica do OP está centrada na disputa democrática pela alocação dos recursos públicos. Esta alocação está intimamente relacionada com localização, portanto, é espacial. Onde serão aplicados os recursos? Em que região da cidade? Quem serão os beneficiados? É um jogo de poder que decide os investimentos, ou pelo menos parte deles.

Durante as várias administraçóes do PT, a parcela do Orçamento que esteve em disputa claramente apontou para um lado, como vários balanços já apontaram (os próximos quatro parágrafos recuperam questôes já discutidas em Lahorgue, 2007 e 2011).

Uma das coisas mais propagandeadas pelo Partido dos Trabalhadores a respeito do OP foi a existência de uma inversão de prioridades na alocação de recursos da Prefeitura. Anteriormente e de forma bastante tradicional no Brasil, a maior parcela dos investimentos era feita nas regióes da cidade onde habitavam as classes médias e alta, reforçando uma relação centro-periferia, como já mencionado neste texto. A pergunta a ser feita, portanto, é: existiu um efeito redistributivo (em direção aos lugares mais carentes) trazido pela dinâmica do OP?

A resposta inicial é sim. Por que inicial? Porque isto considera apenas a parcela do Orçamento decidido pelo mecanismo do OP. Nem toda a verba de investimentos passava (e passa uma parcela cada vez menor nos dias atuais) pelas assembléias populares decisórias.

2 Para uma crítica às teorias neoclássicas de localização residencial, ver Abramo (2007). 
De qualquer maneira, examinando as peças orçamentárias que passaram pelo OP, pode-se ver que há uma correlação bastante visível entre as regiões do Orçamento Participativo, com renda média menor, e o volume maior de investimentos per capita. Assim, entre 1996 e 2002, a Região Extremo Sul foi a que mais recebeu investimentos, na ordem de $\mathrm{R} \$ 728,17$ per capita, seguida por Nordeste ( $\mathrm{R} \$ 562,91$ ), Cristal ( $\mathrm{R} \$ 371,56)$, Glória ( $\$$ \$369,73) e Lomba do Pinheiro ( $\$ 318,44)$. No outro extremo, estão Partenon ( $\mathrm{R} \$ 130,57)$, Noroeste $(\mathrm{R} \$ 61,60)$ e Centro com $\mathrm{R} \$$ 42,82 per capita (Tartaruga, 2003, p. 70).

Outra forma de verificar o efeito redistributivo do OP foi feito por Marquetti (2002). Este autor mapeou o número de obras por grupo de mil habitantes nas Regiões e comparou com a renda per capita no período de 1989 a 2000. O resultado foi praticamente o mesmo obtido por Iván Tartaruga. A Região Nordeste, a de menor renda, obteve a melhor colocação em relação ao número de obras executadas por mil habitantes, com mais de 3,8 obras para cada 1000 habitantes; enquanto a Região Centro, de maior renda, teve a menor relação obras/mil habitantes: número inferior a duas. Confirmando esta tendência, Lomba do Pinheiro e Restinga, também Regiões com índices altos de pobreza, aparecem com o número de 3,2 a 3,8 obras por mil habitantes. Tentando mostrar que outros indicadores (além da renda) também demonstram o efeito redistributivo, ele cruzou os dados relativos aos investimentos nas Regiões com a porcentagem de mães com primeiro grau incompleto e filhos nascidos vivos, porcentagem de domicílios em núcleos e vilas irregulares e porcentagem de habitantes com menos de 15 anos. Como já esperado, de forma geral, quanto maiores estas porcentagens, maior o investimento realizado através do mecanismo do Orçamento Participativo.

Sendo assim, pode-se afirmar que o lado mais beneficiado foi o dos mais pobres e geograficamente o das regiões anteriormente negligenciadas. Outro contraste em relação ao passado de Porto Alegre esteve relacionado à questão habitacional. Como será visto alguns parágrafos adiante, o déficit habitacional na cidade continua grande e, evidentemente, não foi resolvido pela passagem do Partido dos Trabalhadores na Prefeitura da capital. Mas nesta parte do texto é importante frisar que a prefeitura sob governo petista tentou frear, pelo menos parcialmente, o tradicional processo de expulsão dos pobres para a periferia na forma de urbanização de favelas, no mesmo local onde elas estavam situadas, ainda que encravadas no centro da cidade (e com a classe média em volta). Ao mesmo tempo, uma política de regularização fundiária buscou garantir, em áreas de ocupação consolidadas, a permanência dos moradores no local onde se encontravam. Isto é importante porque reconhece e incorpora estas habitaçôes (ainda que precárias) à cidade formal, tornando mais difícil o processo de expulsão para a periferia.

Existem duas urbanizações de favelas bastante emblemáticas, não só deste programa de política habitacional, mas da própria disputa pelo espaço da cidade: a da Vila Planetário e da Vila Lupicínio Rodrigues. Ambos, assentamentos irregulares incrustados em zonas centrais e bastante valorizadas de Porto Alegre (o que significa, entre outras coisas, estarem localizadas no meio de bairros de classe média). $\mathrm{O}$ 
fato de o governo ter tido não só respaldo eleitoral, como também do processo do Orçamento Participativo, não significou falta de contestação sobre a regularização e urbanização das duas vilas no local onde se encontravam. A Vila Planetário - primeira experiência deste tipo na cidade - além de "abaixo-assinados" da população das redondezas, sofreu a contestação de vereadores com o argumento que o Plano Diretor vigente na época (o de 1979, anterior ao Plano proposto pelo PT e atualmente vigente) considerava a área como praça pública (área verde) e, portanto, impossibilitaria a permanência da população ali. Na Vila Lupicínio aconteceu algo semelhante, ainda que muitos anos depois. A favela, no meio do bairro de classe média Menino Deus, sempre foi considerada por uma grande parcela da população do entorno como um "problema" (era comum após roubos e furtos nas imediações o ladrão usar o local como rota de fuga e/ou esconderijo). O resultado foi que, depois de aprovado pelo OP e na iminência do início das obras, circulou pelo bairro (apoiado pela associação dos moradores - de classe média) um abaixo-assinado pedindo a remoção e não a urbanização da vila, com o argumento de que em outro lugar, mais amplo, seria mais fácil a construção de habitações dignas. Em outras palavras, reconhecendo e apoiando o direito da comunidade a uma habitação condigna, desde que isto não acontecesse ali, tão perto da assustada classe média.

Se a disputa por localizações é uma geografia do poder, os exemplos descritos acima corroboram a afirmação de que a balança pendeu, pelo menos em algumas ocasióes, para os mais pobres. Mas também deve ser escrito que não houve a resolução dos problemas habitacionais da cidade. Em um levantamento recente feito pelo Departamento Municipal de Habitação (Demhab) foram contabilizados 75.656 domicílios em situação de irregularidade fundiária em Porto Alegre (Prefeitura Municipal de Porto Alegre, 2009, p. 67). A localização da maioria delas? Em regióes distantes das áreas centrais e, portanto, periféricas. ${ }^{3}$

A saída do Partido dos Trabalhadores depois de 15 anos no Governo Municipal (entre 1989 e 2004) tem redesenhado a geografia do poder, uma mudança ao mesmo tempo lenta, mas firme. O Orçamento Participativo não deixou de existir, políticas de construção de habitações de interesse social continuam em atividade e outros exemplos de uma certa "continuidade" poderiam ser apontados. Mas ao mesmo tempo, há um esvaziamento das funções e discussões do OP pela introdução do conceito de Governança Solidária Local, um fórum executivo e não deliberativo tendo como norte a corresponsabilidade. Esta esfera é uma parceria permanente entre Poder Público, iniciativa privada e o chamado terceiro setor em busca de "soluções" para os problemas da cidade. Ora, um fórum executivo que

Estes números correspondem ao levantamento realizado em 1999 e atualizado em 2005. Também deve ser destacado que a metodologia do Demhab difere do IBGE, ainda que não haja espaço para discutir estas diferenças metodológicas neste texto. O número de domić́lios em situação precária, divulgado recentemente pelo IBGE dentro do cronograma de difusão dos resultados do Censo Demográfico 2010, é de 56.024 moradias. Mesmo com estas divergências numéricas, um fato não muda: a situação ainda não foi resolvida. E, aliás, se for levado em consideração apenas a metodologia e os dados do IBGE, a questão se configura pior, pois no Censo de 2000 foram contabilizadas 39.816 unidades em aglomerados subnormais, ou seja, não só a questão habitacional não foi resolvida como aumentou o número de famílias vivendo em condiçōes inadequadas na cidade. 
chama a comunidade e empresários para discutir a cidade, só pode entrar em conflito com muitas das deliberações do OP, além de, como escreveu Baierle (2005, p. 49), substituir políticas de emancipação social pela integração subalterna às classes burguesas locais. Uma das formas de se perceber este esvaziamento do OP é através da quantidade demandada de obras efetivamente executadas: um levantamento da ONG Cidade (2010, p. 03) mostra que, entre 2005 e 2010, apenas $41 \%$ das obras demandadas foram concluídas, com o ápice do definhamento em 2010. Neste ano, das 191 obras listadas pelo OP, apenas 5 foram concluídas.

Mudanças de governo, com administrações que tendem a enxergar a cidade de maneira distinta da anterior, tendem a produzir (ou incentivar) formas de ocupação do território também diferentes. Na verdade, o que se tem visto nos últimos anos é um retorno às soluções privadas de gestão e uso do solo. O que se quer dizer com isso? Não que todo o arcabouço jurídico-institucional trazido pelo Estatuto da Cidade ou mesmo a própria legislação (Plano Diretor de Desenvolvimento Urbano Ambiental) municipal tenham sido jogados fora. Mas o eixo principal de desenvolvimento, atualmente, está no mercado, no sentido que a produção de espaço na cidade está sendo feita, muito mais a partir da promoção e construção imobiliária privada, do que por indução de políticas públicas. O resultado mais imediato do ponto de vista espacial é a fragmentação do território, pulverizado numa miríade de construções de habitações voltadas para as classes médias e altas, que impactam sobre os bairros onde esta dinâmica é mais forte, trazendo adensamento, verticalização, engarrafamentos de trânsito, enfim, modificando o cotidiano de localidades e afetando as relações entre os diversos bairros da cidade.

Esta mudança de eixo foi favorecida sem dúvida pela conjuntura brasileira de crescimento econômico e ampliação de crédito impulsionada pelo Programa de Aceleração do Crescimento (PAC) do Governo Federal e, nas áreas urbanas, principalmente pela disponibilização de dinheiro para financiamento de habitações. Como mostra Paulo Soares (2010), este novo momento da economia brasileira é acompanhado por um processo de reestruturação dos capitais inseridos na promoção e produção imobiliária. No caso de Porto Alegre, o resultado prático foi a expansão do setor via associações, fusões e aquisições de grupos promotores e construtores locais por grupos nacionais. No Brasil, tradicionalmente o mercado imobiliário era disperso e pulverizado em pequenas e médias empresas com atuação local. Isto tem mudado e agora há grandes empresas capitalizadas na bolsa de valores (inclusive em associação com o capital internacional) atuando na capital gaúcha.

A chegada de grandes grupos e o ritmo intenso de novas construções, inclusive de "novos e planejados" bairros (para uma descrição mais completa ver novamente Soares, 2010), tem produzido não só uma cidade mais fragmentada, mas também tem pressionado para cima o preço da terra. Um exemplo pode ser visto a partir de dados disponíveis pelo Secovi-RS (Sindicato da Habitação): o preço médio de venda de um apartamento usado de 3 dormitórios em Porto Alegre subiu 101\%, entre 2003 e 2010 . Enquanto isso, a inflação medida pelo IPCA (Índice de Preços ao Consumidor Ampliado) no período foi de 43,02\%. 
O que se tem nos dias de hoje, portanto, é uma situação onde ao mesmo tempo os grupos e setores populares têm diminuído sua influência e capacidade de produzir espaço por conta de mudanças na política local, e onde a própria competência de influir dos cidadãos é subordinada às dinâmicas que estão além do território da cidade, primordialmente nacionais no caso da dinâmica imobiliária de Porto Alegre, mas que podem vir a ser até mesmo internacionais - como na questão dos encargos impostos pela FIFA às cidades-sedes da Copa do Mundo. Resumo: perda de controle local, menos importância ainda para OP e conselhos populares locais.

\section{Conseqüências das transformações urbanas}

É neste contexto que a cidade se apresenta para receber os jogos do campeonato mundial de futebol e no qual as obras associadas à competição são apresentadas para a população. Quais as conseqüências no/para o espaço urbano? Onde estão localizadas as obras? Qual o sentido desta localização?

Localização, neste texto, tem o sentido de ser um espaço relativo - para retomar a discussão de espaço de David Harvey (2006) - e, portanto, uma relação social. Este conceito é um dos fundamentos das ciências que se ocupam do espaço, não porque pode ser mensurado em quilômetros ou por qualquer outro sistema de medidas, como um espaço absoluto. E sim porque remete à posição que qualquer Ser ocupa dentro de uma estrutura relacional, dentro de uma estrutura de coabitações onde a distância precisa ser considerada em termos de intensidade qualitativa da relação, não no sentido métrico (Martins, 2007, p. 48). Em palavras mais simples: todos os seres precisam se posicionar em relação a outros seres e objetos. Aliás, mais especificamente, todos os seres precisam se posicionar e se localizar no ambiente construído que chamamos de cidade. Distribuição, extensão e distância, deste modo, passam a ser atributos do ser e das relações sociais, configurando a localização como primordialmente relativa e relacional.

A partir disso, podemos novamente olhar a descrição das obras e o mapa apresentado algumas páginas atrás e perguntar: o que chama a atenção?

Duas coisas primordialmente. Uma, a questão da localização tanto das obras quanto das Áreas Especiais de Interesse Social (AEIS). E o outro é o próprio aparecimento destas Áreas no mapa, já que a matriz de responsabilidades não menciona questões habitacionais como parte do pacote de Copa. Áreas Especiais de Interesse Social, pela legislação brasileira, são aquelas destinadas à produção e à manutenção de habitação de interesse social, ou seja, qualquer projeto de urbanização de assentamentos informais (favelas), ou mesmo, qualquer obra que interfira em áreas habitadas por população de baixa renda que precisa, obrigatoriamente, ter especificado e destinado AEIS para urbanização e/ou reassentamento. É por isso que aquelas áreas foram mapeadas. Algumas das obras viárias previstas afetarão aglomerados populacionais autoproduzidos. Assim, em 28 de dezembro de 2010, a Prefeitura Municipal publica no Diário Oficial a lei complementar nº 663 que institui áreas 
que atendam à Demanda Habitacional Prioritária $(\mathrm{DHP})^{4}$ associadas ao Programa Minha Casa Minha Vida do governo federal. Mesmo que não apareça diretamente na redação da lei a ligação disto com as obras da Copa, os movimentos sociais da cidade passaram a tratar estas áreas como as "AEIS da Copa”, pois a própria prefeitura anunciou que remoções provocadas pelos novos empreendimentos poderiam ser destinadas a estas localidades.

O fato de reassentamentos não aparecerem na Matriz de Responsabilidade mas serem uma conseqüência de fato das intervenções no espaço urbano - dá uma medida da ordem de prioridades de um evento como a Copa do Mundo e da sujeição do grupo político atual a estas prioridades: primeiro, mobilidade, depois, habitação.

$\mathrm{Na}$ verdade, com exceção da reforma do estádio Beira-Rio, todas as obras listadas e previstas dizem respeito à mobilidade. E esta mobilidade, na prática, significa obras viárias, reformas em vias de circulação para alargamento de leito carroçável, prolongamento de avenidas e novos viadutos com o propósito de fazer transitar de modo mais fácil os automóveis. Com a melhora nas condições econômicas do país e de vida da população nos últimos anos, o fenômeno da proliferação de carros particulares nas cidades brasileiras tem sido enorme. No caso de Porto Alegre, a frota de veículos em circulação cresceu de 527.131 em 2004 para 701.576 em junho de 2011, segundo dados do Departamento de Trânsito estadual (Detran - RS). Isto representa um aumento percentual próximo a 33\% no período e mais de $174 \mathrm{mil}$ veículos. Enquanto a isso, é importante relembrar, a população entre 2000 e 2010 teve um acréscimo de pouco mais de 48 mil pessoas. $O$ resultado prático é uma média muito próxima de um carro para cada dois habitantes na capital gaúcha, atualmente. Como lembra Vasconcellos (2001, p. 116), a mobilidade aumenta quando a renda aumenta e este pode ser considerado um fenômeno universal. Derivado disto, o uso de modos diversos de transporte também é altamente influenciado pela renda, o que ajuda a explicar a troca de transporte público pelo individual por uma parcela cada vez maior da população. O que se tem, então, é uma resposta circular do Poder Público: aumento de automóveis significando aumento de investimentos na quantidade de vias, que tem como conseqüência mais estímulo à compra de automóveis, que faz novamente o círculo se fechar: mais investimentos em elevados, avenidas, alargamentos e extensões de ruas. E é exatamente isto que as obras listadas para a Copa parecem fazer: perpetuar o ciclo vicioso de investimentos destinados à locomoção individual e à classe média.

Isto tudo não é contraditório com o fato de haver investimentos previstos também para o transporte coletivo, a partir da proposta de implantação dos BRTs. Um primeiro indicador é o monetário: a verba para a adequação das 3 vias previstas no projeto dos BRTs corresponde à $\mathrm{R} \$ 104$ milhóes, um pouco menos de $1 / 5$ do custo estimado total das obras, 524,9 milhões de Reais (lembrando também que nesta despesa não está contabilizada verba de reforma/ampliação do Aeroporto Salgado

4 A Demanda Habitacional Prioritária é a parcela da demanda por Habitação de Interesse Social destinada à população com renda familiar igual ou inferior a 5 (cinco) salários mínimos, como define o artigo 22 do Plano Diretor da cidade. 
Filho). O segundo indicador relaciona-se exatamente com o fato de ser adequação de vias. Decorrência de as avenidas onde passarão os BRTs já possuírem corredores exclusivos para ônibus. A separação da circulação do transporte coletivo dos automóveis particulares, através de canaletas, começou a ser implantado em Porto Alegre a partir de 1979, estando presente hoje nas principais avenidas da cidade. Conseqüentemente, o que acontecerá não é uma novidade em termos de circulação e uso de vias urbanas pelo transporte coletivo, mas uma modernização (sem entrar aqui no mérito da palavra "modernização"). Não é nosso interesse discutir se a proposta de BRTs é a melhor solução técnica para o transporte coletivo, mas entender as transformações todas no contexto de sua abrangência sobre o território e da capacidade de indução na ocupação do espaço. Portanto, por ser uma reforma de corredores exclusivos para ônibus já existentes, por um lado, pode-se dizer que não há alteração significativa no território onde passarão os novos coletivos. Por outro lado, os BRTs afetarão quem mora mais longe do centro histórico da capital. Um dos motivos da reforma - como já citado no início deste texto - é reduzir o volume de ônibus que se deslocam por dia ao Centro da cidade, 33 mil em média. Para que isto possa acontecer, os passageiros de ônibus procedentes dos bairros da Capital e da Região Metropolitana desembarcarão nos portais e no terminal Triângulo. Desse terminal, tomarão ônibus articulados especiais para seguir viagem dentro da cidade. É uma solução que pretende eliminar problemas de congestionamento e baixa velocidade (principalmente nos horários de pico do trânsito), criando uma rede de linhas troncais e alimentadoras. Temos um aparente paradoxo, portanto: $o$ número de veículos aumenta em velocidade muito maior que a população e a solução empregada visa reduzir o número de ônibus e não de carros particulares. E para que isso aconteça, os habitantes de bairros periféricos e provenientes de cidades da Região Metropolitana terão que tomar mais de uma condução para chegar ao centro de Porto Alegre, visto que a partir da inauguração do sistema, muitas linhas não se dirigirão mais para o centro e sim para algum dos Portais. Resumindo: em termos de localização, os mais afetados serão os habitantes de lugares distantes dos novos Corredores de Ônibus, pois mesmo que o tempo de deslocamento se torne mais eficiente dentro da via segregada (o que ainda deverá ser comprovado), este morador será obrigado a utilizar mais de um ônibus, algo que hoje não é necessário: a linha alimentadora e a linha BRT. Não há ainda evidência de que isto melhorará a qualidade de deslocamento desta população ou mesmo diminua o tempo de viagem total. E, diga-se de passagem, até o momento em que estas linhas estão sendo escritas e mesmo com as obras em andamento, a Prefeitura Municipal não apresentou nenhum estudo que comprove qualquer afirmação sobre a melhoria no acesso aos bairros distantes.

O que se tem então é a volta da questão da localização como fator para o entendimento das dinâmicas que podem ser encadeadas com as obras da Copa. Isto aparece claramente quando olhamos novamente para o mapa: algo que deve chamar a atenção é exatamente a posição - no sentido mesmo de localização - em 
que se encontram as Áreas passíveis de intervenção para regularização fundiária e construção de habitações populares. E que posição é essa? Uma localização periférica. A grande maioria das AEIS está distante de locais que podem ser considerados centrais em Porto Alegre. Assim, está se repetindo um padrão clássico no desenvolvimento das cidades brasileiras e que inclusive parecia superado: pobres ficam em áreas distantes e periféricas e classes médias e altas em áreas centrais.

É preciso esclarecer mais uma coisa: a expressão "áreas centrais" não se refere necessariamente ao bairro Centro histórico, por exemplo. São áreas centrais das cidades aquelas nas quais a infraestrutura (calçamento, serviços de iluminação, água, esgoto, etc.) existe e funciona e a acessibilidade é a melhor: locais onde existe escolas, comércio, serviços e empregos abundantes, vias de acesso fácil e com amplo sistema de transporte para outros lugares, etc. Neste sentido, bairros como Menino Deus, Moinhos de Vento, Petrópolis entre outros devem ser considerados áreas centrais. Por outro lado, bairros como Sarandi e Lomba do Pinheiro são periféricos. Em conseqüência, reforçamos novamente o fato de a localização ser relativa: o Centro só é centro em relação a uma periferia e as dinâmicas de crescimento urbano podem modificar estas posiçôes. Levada adiante, a discussão da centralidade pode inclusive ser muito rica em proposições para o entendimento do espaço intra-urbano, através do reconhecimento das multiplicidades de centros e da ideia de centralidades vividas (Serpa, 2011, p.104).

O significado disto é que as cidades podem ser entendidas, entre outras coisas, como uma arena de disputas por localizações (Villaça, 1998). E se é disputa, temos vencedores: a estes os melhores bairros e localizações (os mais ricos), enquanto aos mais pobres cabe se localizar em bairros periféricos. $\mathrm{O}$ conjunto de intervenções urbanas previstas deve provocar um reforço da dinâmica centro-periferia, pois vejamos: as obras na região central são de melhorias viárias que, como toda melhoria viária, com certeza provocará valorização imobiliária no entorno; as obras na periferia são de construção de moradia para os pobres, mesmo que a infraestrutura nestas localizações seja deficiente e, como visto, o próprio deslocamento para estas regiões será alterado profundamente com o novo desenho do transporte coletivo.

Além de reforçar uma dinâmica tradicional de maiores investimentos em áreas já abundantes de infraestrutura, enquanto áreas carentes recebem menos dinheiro, o conjunto de obras parece ignorar um dos preceitos de um bom planejamento: não tratar separadamente as várias partes constituintes de uma cidade, pois a proposta para a Copa nitidamente não integra mobilidade e habitação. Aliás, como já comentado neste texto, a habitação aparece como um entrave atrapalhando as obras de mobilidade. A prioridade é como os visitantes vão se deslocar pela cidade e não os moradores da própria. Mesmo com as obras e as intervenções urbanas ainda não terminadas, já existe um exemplo emblemático: as obras de duplicação da Av. Tronco. Como descrito na primeira seção deste trabalho, para o alargamento/duplicação da via é necessária a remoção de aproximadamente 1.500 famílias que moram na área de intervenção. O que se tem no presente momento (final de 2012)? O alargamento de partes da Avenida já começou, mas as novas unidades habitacionais 
para os moradores afetados sequer tem empreiteira contratada ainda. Portanto, os moradores estão sendo gradativamente retirados antes da construção de suas novas moradias. A Prefeitura está resolvendo esta questão fornecendo bônus moradia para as famílias afetadas. A previsão da Administração Municipal é fornecer 400 bônus como forma de liberar áreas para as obras. Com o preço da terra e, portanto, das habitações se valorizando constantemente nos últimos anos, muitas famílias ao receber o bônus acabam comprando casa em outros municípios da região Metropolitana, como a própria propaganda alardeia:

Somando o seu bônus com o do filho, hoje seu vizinho na Vila Cruzeiro, Marina, 62 anos, comprou uma casa para a família em Alvorada, no valor de R 104.680,00, cuja titularidade será de $50 \%$ para cada morador cadastrado. 'Pra mim foi muito bom, porque conseguimos uma casa mais espaçosa. Pegando o bônus, a gente escolhe onde quer morar', disse. O esposo, Adão, 74 anos, concorda que foi a escolha acertada pra a família. 'Estou contente. Além de nós, outros vizinhos sem condições terão uma casa ótima para viver', avaliou. O Bônus Moradia é uma opção oferecida às famílias reassentadas em razão das obras de mobilidade urbana da Copa 2014, cadastradas pelo Departamento Municipal de Habitação (Demhab). Nesta modalidade, a aquisição da casa própria se dá com maior rapidez. Além do bônus, o município está pagando indenizações e disponibilizando o aluguel social.

(Demhab, 2012)

Não está em discussão aqui se algumas famílias individualmente possam ficar contentes em sair da região onde sempre moraram. O que a citação nos mostra é que as soluções de remoção e reassentamento estão sendo planejadas de forma a confrontar um dos acordos firmados e registrados em ata pelo processo do Orçamento Participativo já há alguns anos. Este acordo diz duas coisas: 1) a prioridade de construção de habitações e regularização fundiária deve ser da permanência dos moradores no mesmo local, sempre que possível; 2) quando isto não for possível e o deslocamento com reassentamento for a única solução, deve ser garantida a permanência da população deslocada na mesma região do OP. Tudo isso tem sido ignorado em nome dos "compromissos com a Copa", como já havia demonstrada a primeira das remoçóes causadas pelas obras, a transferência da Vila Dique para a ampliação da pista do Aeroporto Salgado Filho.

\section{Considerações finais}

É preciso reafirmar aqui que o conjunto de obras em andamento reforçam centralidades já existentes e concentram investimentos em regióes da cidade onde a renda média dos habitantes é mais alta. Além disso, todo este processo passa ao largo das decisões tomadas pelas assembléias e instâncias do Orçamento Participativo, mostrando como a participação atualmente tem uma posição subordinada nas dinâmicas urbanas de Porto Alegre. Nenhuma obra da Copa entrou em discussão no OP; aliás, as prioridades definidas para aplicação de recursos para o período 2012/2013 pelas Regiões do OP não são de mobilidade ou duplicação de vias urbana: das 17 
Regiões, 10 escolheram a temática "habitação" como prioritária (um reflexo da questão habitacional irresolvida na cidade) e somente a Região Nordeste escolheu uma prioridade semelhante às obras da Copa, que é "pavimentação" (Prefeitura Municipal de Porto Alegre, 2012).

A partir disso, o que se deve esperar até 2014 ?

A tendência parece ser a continuidade de processos de valorização imobiliária, que tem como conseqüência mais óbvia o encarecimento da moradia para todos, inclusive os mais pobres. Esta valorização empurra os pobres para ainda mais longe, onde a terra ainda é relativamente barata. Isto pode ser comprovado atualmente pela localização das AEIS, como visto anteriormente. Aliás, quando pela dinâmica de crescimento urbano um bairro começa a deixar de ser periférico, uma das primeiras coisas que acontece é a substituição de moradores mais pobres, a partir da construção de empreendimentos imobiliários para classes mais altas, e o consequente aumento do preço da terra como demarcador da nova posição do bairro na localização relativa dentro da cidade.

Reforçamos que a perspectiva, do ponto de vista de transformações positivas para a população mais pobre não é muito boa pelos motivos expostos anteriormente. Mas também deve ser lembrado que Porto Alegre tem um histórico de lutas sociais e populares bastante intenso. Aliado a isto, existe um amplo leque de Leis que podem apoiar a luta dos que querem ter o direito à cidade plenamente, não uma cidade fragmentada em interesses particulares. O Estatuto da Cidade e a própria legislação municipal possuem vários mecanismos e instrumentos à disposição das lutas sociais, como por exemplo, a função social da propriedade. Mas estes instrumentos não funcionam por si só. A existência de um instrumento urbanístico como as AEIS, sem dúvida, foi um avanço no direito à moradia, mas e o direito à cidade? Lutar para que a Periferia se torne Centro, sem expulsar os moradores mais pobres, também deve ser uma luta de todos. Da mesma maneira como se deve lutar para que o legado da Copa não seja pura especulação imobiliária e obras que reforcem a periferização da pobreza. Ainda é incerto o resultado de todas as lutas e movimentos que se iniciam e as contradições desencadeadas pelos acontecimentos aqui expostos. É assim mesmo: o espaço é produzido social e contraditoriamente, com resultados muitas vezes não previstos ou pretendidos pelas diversas forças sociais envolvidas. OEURE 


\section{Referências bibliográficas}

Abramo, P. (2007). A cidade caleidoscópica: coordenação espacial e convenção urbana. Rio de Janeiro: Bertrand Brasil.

Baierle, S. (2005). Lutas urbanas em Porto Alegre: entre a revolução e o transformismo. Porto Alegre: Cadernos da Cidade.

Cidade - Centro de Assessoria e Estudos Urbanos (2010). De olho no Orçamento, 29 (outubro de 2010).

Costa, B. M. (2001). Porto Alegre e sua região metropolitana. In Prefeitura Municipal de Porto Alegre, Relatório de Indicadores Sociais de Porto Alegre - ano III - 2000 (pp. 07-51). Porto Alegre: Prefeitura Municipal.

Departamento Municipal de Habitação (Demhab) (2012). Avenida Tronco: Bônus éoportunidadepara qualificar moradias. Acesso em 30 de outubro de $2012 \mathrm{em}$ http://www2.portoalegre.rs.gov. br/demhab/default.php?p_noticia=155902\&AVENIDA+TRONCO:+BONUS+E+O PORTUNIDADE+PARA+QUALIFICAR+MORADIAS

Harvey, D. (2006). Space as a keyword. In N. Castree \& D. Gregory (Orgs.), David Harvey: A critical reader (pp. 270-293). Oxford: Blackwell.

Instituto Brasileiro de Geografia e Estatística (IBGE) (n.d.). Censo Demográfico 2010. Acesso em: http://www.censo2010.ibge.gov.br/resultados

Lahorgue, M. L. (2007). A esquerda no poder local: Porto Alegre e o Partido dos Trabalhadores. Scripta Nova. Revista Electrónica de Geografía y Ciencias Sociales, 11 (245) (16). Acesso em http://www.ub.es/geocrit/sn/sn-24516.htm

Lahorgue, M. L. (2011). Porto Alegre: espaço e políticas urbanas. In E. B. Costa \& R. S. Oliveira (orgs.), As cidades entre o "real"e o imaginário: estudos no Brasil (pp. 129-152). São Paulo: Expressão popular.

Marquetti, A. (2002). O Orçamento Participativo como uma política redistributiva em Porto Alegre. Trabalho apresentado no $1^{\circ}$ Encontro de Economia Gaúcha. Porto Alegre: 16 e 17 de maio.

Martins, E. R. (2007). Geografia e Ontologia: o fundamento geográfico do Ser. GeoUSP, 21, 33-51.

Prefeitura Municipal de Porto Alegre (2000). Plano Diretor de Desenvolvimento Urbano Ambiental (PDDUA). Porto Alegre: Prefeitura Municipal.

Prefeitura Municipal de Porto Alegre (2009). Plano Municipal de Habitação de Interesse Social. Etapa II - diagnóstico do setor habitacional de Porto Alegre. Porto Alegre: Prefeitura Municipal, fevereiro de 2009.

Prefeitura Municipal de Porto Alegre (2010). Lei Complementar nº 663, de 28 de dezembro de 2010. Diário Oficial de Porto Alegre. Edição 3920. Quarta-feira, 29 de dezembro de 2010.

Prefeitura Municipal de Porto Alegre (2012). Orçamento Participativo. Acesso em http://www2.portoalegre.rs.gov.br/op/default.php

Prefeitura Municipal de Porto Alegre (n.d.). Projeto BRT/Portais da cidade. Acesso em 15 de junho, 2011, em: http://lproweb.procempa.com.br/pmpa/prefpoa/smgae/usu_doc/portais.pdf

Raffestin, C. (1993). Por uma geografia do poder. São Paulo: Ática.

Santos, M. (1980). Por uma geografia nova. São Paulo: Editora Hucitec - Humanismo, Ciência e Tecnologia.

Santos, M. (1996). A natureza do espaço: técnica e tempo, razão e emoção. São Paulo: Editora Hucitec Humanismo, Ciência e Tecnologia. 
Serpa, A. (2011). Lugar e centralidade em um contexto metropolitano. In A. F. Carlos, M. L Souza \& M. E. Sposito (Orgs.), A Produção do espaço urbano: agentes e processos, escalas e desafios. São Paulo: Contexto.

Soares, P. R. R. (2010). Del presupuesto participativo a los megaproyectos: la producción del espacio urbano en Porto Alegre en el siglo XXI. Scripta Nova. Revista Electrónica de Geografía y Ciencias Sociales, 14(331) (28). Acesso em http://www.ub.es/geocrit/sn/sn-331/sn-33128.htm

Tartaruga, I. G. P (2003). O Orçamento Participativo de Porto Alegre: o lugar e o território do cidadão. Dissertação de Mestrado, Geografia, Universidade Federal do Rio Grande do Sul (UFRGS).

Vasconcellos, E. A. (2001). Transporte público, espaço e equidade: análise das políticas públicas. São Paulo: Annablume.

Villaça, F. (1998). Espaço intra-urbano no Brasil. São Paulo: Studio Nobel. 